processing metals and ceramics are all being achieved by the use of plasma processing. The purpose of this symposium is to bring together scientists and engineers active in the plasma processing of materials to discuss both fundamental and technology related issues. Contributed papers are invited in the following areas:

- Modeling (to include both thermal and low-pressure plasmas)

- Diagnostics

- Plasma synthesis

- Surface modification, including coatings

- Melting and extractive

- Low-pressure plasma, PECVD, and plasma etching

Symposium Chairs:

Diran Apelian

Professor and Head

Materials Engineering

Drexel University

Philadelphia, PA 19104

(215) 895-2322

Julian Szekely

Professor

Materials Science and Engineering

MIT

Cambridge, MA 02139

(617) 253-3236

\section{Symposium L}

\section{Materials for Aerospace Applications}

The Materials Research Society and its Southern California Section are organizing this symposium to be held during the MRS Annual Spring Meeting in Anaheim, CA. This is the first such symposium to be organized by MRS in recognition of the materials-related issues specifically and critically important to applications in the aerospace and space industry. As such, the objectives of the symposium are: (1) to promote greater awareness among materials scientists of such practical issues, and of related research opportunities and challenges; (2) to enhance interaction between materials research and materials application oriented communities, as well as cross-fertilization of ideas.

The topics/areas to be emphasized are:

- Metal matrix composites

- Ceramics for high-temperature applications

- Organic matrix composites

- Materials response in low orbits to oxygen-radical interactions

Symposinm Chairs:

A. Madhukar

Department of Materials Science

University of Southern California

Los Angeles, CA 90089-0241

(213) 743-6929

L. Leger

NASA Johnson Space Center

Mail Stop ES-5

Houston, TX 77058

(713) $483-2059$

\section{MRS}

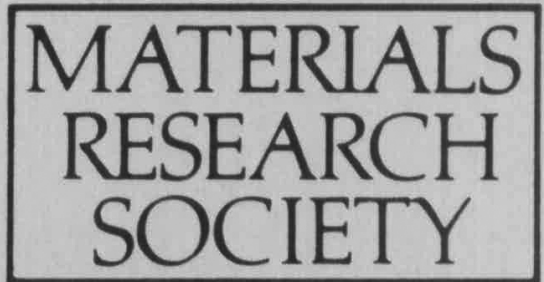

\section{Candidates Sought for Graduate Student Awards at 1987 Spring Meeting}

The Materials Research Society announces the availability of several awards for graduate students conducting research on a topic to be addressed in a symposium at the 1987 Spring Meeting. Each award will consist of a cash grant of $\$ 250$, to be presented at ceremonies during the meeting, and a waiver of the meeting registration fee.

Criteria for selection are:

1. Graduate standing in a recognized academic program in materials science, metallurgy, ceramics, or polymers; physics or chemistry; geology or mineral science; electrical, civil, mechanical, mining, or nuclear engineering; or other materials-related field.

2. Participation in the 1987 Spring Meeting by being an author or coauthor of a paper presented in one of the symposia.

3. Outstanding performance in the conduct of the research project and promise for future substantial achievement in materials research as judged by the faculty advisor.

4. Significant and timely research results as judged by the chair of the appropriate symposium.

Application materials required are:

1. Application form obtainable from MRS Headquarters.

2. Abstract of paper to be presented at the meeting

3. Letter of support from research supervisor.

Deadline for completed application is February 1, 1987. Awards will be announced March 1, 1987. Obtain application form and submit completed application to:
John B. Ballance
Executive Director
Materials Research Society
9800 McKnight Road, Suite 327
Pittsburgh, PA 15237
Telephone: (412) 367-3003 